TẠP CHÍ KHOA HỌC ĐẠI HỌC TÂN TRÀO

ISSN: 2354 - 1431

http://tckh.daihoctantrao.edu.vn/

\title{
NGHIÊN CÚUU THÀNH PHẦN HÓA HỌC VÀ VI SINH VẬT CỦA RƯợU VANG SIM THU HÁI TẠI XÃ CÔN LÔN HUYỆN NA HANG, TỈNH TUYÊN QUANG
}

\author{
Hoàng Thị Lệ Thuong ${ }^{a^{*}}$ \\ ${ }^{a}$ Truò̀ng Đại học Tân Trào \\ *Email: hoangthilethuong@gmail.com
}

\section{Thông tin bài viết}

Ngày nhận bài:

7/6/2020

Ngày duyệt đăng:

12/8/2020

Tù khóa:

Rhodomyrtus tomentosa, Saccharomyces cerevisiae, rựu vang

\section{Tóm tắt}

Rượu vang là loại đồ uống có cồn nhẹ được lên men trực tiếp từ dịch quả mà không trải qua quá trình chưng cất. Rượu vang sim rừng $\mathrm{Na}$ Hang được sản xuất từ dịch ép quả sim (Rhodomyrtus tomentosa) sử dụng chủng nấm men Saccharomyces cerevisiae S5 đã được nghiên cứu tuyển chọn, định danh theo quy trình sản xuất vang sim rừng $\mathrm{Na}$ Hang [1]. Với mong muốn xây dựng bộ tiêu chí công bố chất lượng cho rượu vang sim, thành phần hóa học, vi sinh vật của vang sim được xác định bằng các phương pháp phân tích hiện đại. Thành phần rượu vang sim thu được có chỉ tiêu hóa học (ethanol $12.5 \mathrm{~g} / 1$, acid bay hơi 3mg/l, hàm lượng rượu bậc cao $328.32 \mathrm{mg} / \mathrm{l}$, hàm lượng ester $281.92 \mathrm{mg} / \mathrm{l}$, hàm lượng aldehyde 34.1 mg/l, không có methanol), vi sinh vật (vi sinh vật hiếu khí là $166 \pm 7 \mathrm{CFU} / \mathrm{ml}$, tổng số nấm men và nấm mốc $4 \pm 0,2 \mathrm{CFU} / \mathrm{ml}$, không phát hiện $\mathrm{E}$. coli, $\mathrm{Cl}$. perfringens, Strep. feacal) và giá trị cảm quan tốt. Thành phần vang sim rừng $\mathrm{Na}$ Hang đạt tiêu chuẩn rượu vang Việt Nam.

\section{Mở đầu}

Vang là loại đồ uống có cồn nhẹ được lên men trực tiếp từ dịch quả (ban đầu chỉ là dịch nho) mà không trải qua quá trình chưng cất, được tàng trữ lâu ngày (hàng chục năm thậm chí hàng thế kỉ) trong những điều kiện nhất định. Vang có hương vị đặc trưng riêng khác hẳn với các sản phẩm lên men khác [2]. Từ thời Ai cập cổ đại con người ta đã biết sản xuất rượu vang. Cũng từ đây, kỹ thuật sản xuất vang được di nhập sang các quốc gia vùng Địa Trung Hải vào khoảng 600 năm trước công nguyên và xuất hiện ở Châu Âu vào khoảng thế kỷ 15 [3].

Năm 1983, ngành công nghiệp sản xuất vang chính thức ra đời nhờ công trình nghiên cứu áp dụng vào thực tiễn của Tiến sĩ Nguyễn Quang Hào và các cộng sự. Cùng thời điểm đó, các loại vang Thăng Long, vang Gia Lâm, vang Đông đô, vang Hoàn Kiếm lần lượt ra đời. Hiện cả nước có hơn 15 doanh nghiệp sản xuất và đóng chai rượu vang với sản lượng mỗi năm khoảng 12 - 13 triệu lít [4]. Một số tác giả ở Đại học Bách khoa Hà Nội, Trung tâm khoa học tự nhiên và công nghệ, Viện công nghệ thực phẩm... đã trình bày các kết quả nghiên cứu của mình về công nghệ vang từ các loại quả: mận, dứa, nho...[5], [6]. Nhờ vậy, nhiều loại vang phổ biến được thịnh hành trên thị trường, giúp cho ngành vang tiến bước một cách vững chắc.

Nguyên liệu sản xuất vang là các loại quả tươi, có đường, protein, vitamin, muối khoáng, không chứa chất độc thì có thể lên men vang [7]. Tùy theo công 
nghệ và yêu cầu về chất lượng sản phẩm cụ thể mà các chủng nấm men sử dụng phải có thêm những yêu cầu cụ thể khác như tạo hương, sử dụng các loại đường khác nhau...

Thành phần hóa học chính của vang gồm ethanol, aldehyde, ester, methanol, rượu bậc cao... Các chỉ tiêu về một số chất gây ô nhiễm trong thực phẩm được Liên minh châu Âu và tiêu chuẩn quốc gia Việt Nam quy định nghiêm ngặt mức tối đa. Theo đó, các giới hạn tối đa cho một số chất gây ô nhiễm trong thực phẩm được đưa ra để bảo vệ sức khỏe của các nhóm dân số nhạy cảm nhất (trẻ em, người già và phụ nữ mang thai). Các chất này bao gồm: Mycotoxin (aflatoxin, ochratoxin A, độc tố fusarium, patulin và citrinin); kim loại (chì, cadmium, thủy ngân, thiếc vô cơ), 3monochloropropane-1,2-diol (3-MCPD), dioxin và biphenyls polychlorin hóa (PCB), melamine, axit erucic, nitrat... Hàm lượng các kim loại nặng là chỉ tiêu thường được phân tích trong vang thành phẩm [7].

Hệ vi sinh vật trong lên men rượu vang tự nhiên tương đối phức tạp và không đồng nhất trong các giai đoạn của quá trình lên men. Phần lớn trong phức hệ vi sinh vật này là nấm men (79 - 90 \%), nấm mốc (9 - 22 \%), số còn lại chiếm tỷ lệ thấp là vi khuẩn không sinh bào tử hoặc có bào tử, xạ khuẩn và micobacter.

Các nghiên cứu về sản xuất rượu vang sim trên thế giới được một vài tác giả công bố nhu "Nghiên cứu về tính ổn định của glycoside flavonoid trong quá trình lên men của rượu vang Rhodomyrtus tomemtosa" của Zhong R.và cộng sự [8]; Sản xuất rượu vang từ Berries of Downy Rosemyrtle của Fenglin $\mathrm{H}$ và cộng sự [9]... Các nghiên cứu sản xuất rượu vang sim ở Việt Nam đã được công bố bao gồm: hoàn thiện quy trình sản xuất vang sim, nghiên cứu sản xuất rượu vang sim, ổn định và nâng cao chất lượng rượu vang sim bằng biện pháp hóa học và sinh học [10], [4]... Các nghiên cứu này chủ yếu tập trung vào các yếu tố kỹ thuật và công nghệ, cụ thể là: quy trình sản xuất vang sim, tối ưu các điều kiện lên men trong quá trình lên men chính dịch quả sim, tối ưu các điều kiện lên men phụ, tỷ lệ phối chế rượu sau lên men, ảnh hưởng của các tác nhân được sử dụng đến khả năng duy trì màu sắc của vang sim, nâng cao chất lượng rượu vang sim trong quá trình tàng trữ...

Trên thị trường có vang Sim Bảy Gáo, vang Sim Sơn, vang Sim Thành Long, vang sim rừng Măng Đen... Thành phần các vang sim trong các nghiên cứu và sản phẩm đã công bố chỉ bao gồm ethanol, hàm lượng đường, chất phụ gia thực phẩm [10]. Thành phần hóa học, vi sinh vật của vang sim rừng $\mathrm{Na}$ Hang là công bố chính thức đầu tiên về thành phần rượu vang sim rừng Na Hang. Việc nghiên cứu thành phần hóa học và vi sinh vật của rượu vang sim thu hái tại huyện Na Hang, tỉnh Tuyên Quang là cần thiết và là cơ sở khoa học cho việc đăng ký và công bố chất lượng sản phẩm rượu vang sim trên địa bàn tỉnh Tuyên Quang.

\section{Vật liệu và phương pháp nghiên cứu}

\subsection{Vật liệu nghiên cúu}

Vang sim được sản xuất từ quả sim tại xã Côn Lôn, huyện $\mathrm{Na}$ Hang, sử dụng chủng nấm men Saccharomyces cerevisiae S5 theo quy trình sản xuất vang sim đã được công bố trong đề tài "Nghiên cứu sản xuất thử nghiệm rượu vang từ quả $\mathrm{Sim}$ (Rhodomyrtus tomentosa) tại xã Côn Lôn, huyện Na Hang"[1].

\subsection{Phuơng pháp nghiên cúu}

Phuơng pháp hóa học

Phuoong pháp xủ lí mẫu

Quả sim được chọn là những quả chín, không dập nát, không bị sâu hay thối ủng. Sau đó, quả sim được rửa sạch đem xay nhỏ bằng máy ép hoa quả, sau đó ép lấy nước để tiến hành lên men.

Xác định hàm luợng đuoòng tổng

Hàm lượng đường tổng trong dịch lên men lên được đo bằng máy chiết quang kế cầm tay để xác định tỉ lệ \% chất khô hoà tan có trong dịch $\left({ }^{\circ} \mathrm{Bx}\right)$.

Từ độ $\mathrm{Bx}$ chuyển đổi thành nồng độ đường tương ứng trong dịch quả, tính theo $\mathrm{g} / \mathrm{l}$ được quy chuẩn về $20^{\circ} \mathrm{C}$.

Xác định trị số $p H$

Trị số $\mathrm{pH}$ của môi trường ban đầu và dịch lên men được xác định bằng máy đo $\mathrm{pH}$.

Xác định tanin theo TCVN - Tanin 2020 [11]

Nguyên tắc: Tanin dễ bị oxi hóa bởi $\mathrm{KMnO}_{4}$ trong môi trường axit với chất chỉ thị indigocarmin sẽ tạo thành $\mathrm{CO}_{2}$ và $\mathrm{H}_{2} \mathrm{O}$, đồng thời làm mất màu xanh của indigocarmin. Quá trình đó diễn ra theo sơ đồ sau:

$$
\text { Tanin }+\mathrm{KMnO}_{4} \underset{\mathrm{H}_{2} \mathrm{SO}_{4}}{\stackrel{\text { Indigocarmin }}{\longrightarrow}} \mathrm{CO}_{2}+\mathrm{H}_{2} \mathrm{O}
$$

Tiến hành: Lấy $1 \mathrm{ml}$ dịch quả sim cho vào bình tam giác $100 \mathrm{ml}$, cho $2,5 \mathrm{ml}$ dung dịch indigocarmin và $75 \mathrm{ml}$ nước cất. Dùng dung dịch $\mathrm{KMnO}_{4} 0,1 \mathrm{~N}$ để chuẩn độ, đến khi xuất hiện màu vàng. Lượng $\mathrm{KMnO}_{4}$ $0,1 \mathrm{~N}$ dùng chuẩn độ là $\mathrm{a}(\mathrm{ml})$. 
Lấy $1 \mathrm{ml}$ dịch quả sim và $5 \mathrm{~g}$ than hoạt tính, đun cách thủy khoảng 10 - 15 phút rồi lọc. Dịch lọc thu vào cốc $100 \mathrm{ml}$, rửa bã than nhiều lần bằng nước cất ở $50^{\circ} \mathrm{C}$. Lọc xong thêm nước cất cho đủ $75 \mathrm{ml}$, cho tiếp $2,5 \mathrm{ml}$ dung dịch indigocarmin và $75 \mathrm{ml}$ nước cất. Dùng dung dịch $\mathrm{KMnO}_{4} 0,1 \mathrm{~N}$ để chuẩn độ, đến khi dung dịch chuyển sang màu vàng thì dừng. Lượng $\mathrm{KMnO}_{4} 0,1 \mathrm{~N}$ dùng chuẩn độ là $\mathrm{b}(\mathrm{ml})$.

Công thức tính:

$$
\mathrm{X} \%=\frac{(\mathrm{a}-\mathrm{b}) \cdot \mathrm{V} \cdot \mathrm{k} \cdot 100 \%}{\mathrm{~V}_{\mathrm{f}} \cdot \mathrm{C}}
$$

Trong đó:

X: Hàm lượng tanin tính theo phần trăm chất khô (\%); a: Lượng $\mathrm{KMnO}_{4}$ chuẩn độ ở bình thí nghiệm (ml); b: Lượng $\mathrm{KMnO}_{4}$ chuẩn độ ở bình đối chứng $(\mathrm{ml})$; V: Thể tích toàn bộ dịch chiết $(\mathrm{ml}) ; \mathrm{V}_{\mathrm{f}}$ : Thể tích dịch dùng để phân tích (ml); C: Khối lượng mẫu phân tích (g); k: Hệ số tanin = 0,00582: Cứ $1 \mathrm{ml} \mathrm{KMnO}_{4}$ $0,1 \mathrm{~N}$ tương đương với $0,00582 \mathrm{~g}$ tanin

\section{Xác định hàm luợng Vitamin C [12]}

Nguyên tắc: Acid L - ascorbic (vitamin C) có tính khử mạnh được oxy hoá bằng dung dịch $\mathrm{I}_{2}$ với chỉ thị là dung dịch tinh bột. Điểm kết thúc của phản ứng nhận biết được nhờ chỉ thị màu xanh khi $\mathrm{I}_{2}$ dư trong dung dịch.

Tiến hành: Lấy $10 \mathrm{ml}$ dịch quả sim cho vào bình tam giác $250 \mathrm{ml}$, cho $5 \mathrm{ml}$ dung dịch $\mathrm{H}_{2} \mathrm{SO}_{4}$ $(1: 10$ hay $180 \mathrm{~g} / \mathrm{l})$ và thêm vài giọt tinh bột, lắc nhẹ rồi chuẩn độ bằng $\mathrm{I}_{2} 0,01 \mathrm{~N}$ tới khi xuất hiện màu xanh.

Kết quả: Lượng acid ascorbic được tính theo công thức sau:

Hàm lượng acid ascorbic trong 1 lít =

$$
\frac{n .0,88 \cdot 1000}{V}(\mathrm{mg} / \mathrm{l})
$$

Trong đó:

n: Số $\mathrm{ml}$ dung dịch $\mathrm{I}_{2} 0,01 \mathrm{~N}$ dùng để chuẩn độ ; 0,88: Số $\mathrm{mg}$ acid ascorbic tương ứng với $1 \mathrm{ml} \mathrm{I}_{2}$ $0,01 \mathrm{~N}$; V: Số ml dịch quả đã lấy để phân tích.

\section{Xác định acid tổng số theo TCVN 8012:2009[13]}

Nguyên tắc: Chuẩn độ trực tiếp các acid có trong mẫu rượu vang sim bằng dung dịch kali hydroxit với chỉ thị màu hỗn hợp.
Acid tổng số gồm các acid bay hơi và không bay hơi trong rượu vang sim. Sử dụng chỉ thị màu hỗn hợp (một thể tích dung dịch $0,2 \%$ metyl đỏ trong rượu và một thể tích dung dịch $0,1 \%$ metylen xanh trong rượu). Lấy $10 \mathrm{ml}$ rượu mẫu, thêm $15 \mathrm{ml}$ nước cất, 5 giọt chỉ thị màu hỗn hợp, dung dịch sẽ ngả màu tím. Chuẩn độ bằng $\mathrm{KOH} 0,1 \mathrm{~N}$ đến khi dung dịch chuyển sang màu xanh lá mạ. Hàm lượng acid (theo acid acetic) trong $1000 \mathrm{ml}$ rượu:

$$
\mathrm{X}=\frac{a \cdot b \cdot 1000}{V}
$$

\section{Trong đó:}

$\mathrm{X}$ : Hàm lượng acid tổng trong 1 lít rượu $(\mathrm{g} / \mathrm{l})$; $\mathrm{a}$ : Thể tích $\mathrm{KOH}$ dùng để chuẩn độ $(\mathrm{ml})$; b: Lượng acid acetic tương ứng với $1 \mathrm{ml} \mathrm{KOH} 0,1 \mathrm{~N}(0,006)$ tính bằng $\mathrm{mg} ; \mathrm{V}$ : Thể tích rượu mẫu phân tích (ml).

\section{Xác định hàm luợng ruọu ethanol}

Xác định hàm lượng rượu ethanol bằng cồn kế theo phương pháp tỷ trọng TCVN 8008:2009: Rượu trắng/ phương pháp thử [14].

Xác định aldehyde tổng số theo TCVN 8009:2009 [15]

Dùng pipet lấy $50 \mathrm{ml}$ mẫu rượu vang sim có chứa $300 \mathrm{ml}$ nước sôi hoặc nước đã loại khí và $10 \mathrm{ml}$ dung dịch $\mathrm{K}_{2} \mathrm{~S}_{2} \mathrm{O}_{5}$. Đậy nắp bình, xoay bình để trộn và để yên 15 phút. Thêm $10 \mathrm{ml}$ dung dịch phosphat - EDTA. Đậy nắp bình, xoay bình để trộn và để yên thêm 15 phút. Thêm $10 \mathrm{ml}$ axit clohydric và khoảng $10 \mathrm{ml}$ tinh bột $0,2 \%$ mới chuẩn bị. Xoay bình để trộn đều, thêm lượng dung dịch iot $0,1 \mathrm{M}$ chỉ vừa đủ để phá hủy lượng bisulfit dư và đưa dung dịch đến màu xanh nhạt.

Thêm $10 \mathrm{ml}$ dung dịch natri borat và chuẩn độ nhanh lượng bisulfit giải phóng bằng dung dịch iot $0,05 \mathrm{M}$ từ buret $10 \mathrm{ml}$ hoặc dung dịch iot $0,02 \mathrm{M}$ từ buret đến điểm kết thúc có màu xanh nhạt như trên, xoay nhẹ bình trong khi chuẩn độ, tránh ánh sáng trực tiếp của mặt trời.

Phuơng pháp xác định hàm luợng rươu bậc cao và ethyl axetat bằng sắc ký khí TCVN 8011:2009[16]

Dùng pipet lấy $10 \mathrm{ml}$ phần mẫu vang sim cho vào bình. Dùng pipet cho thêm $0,1 \mathrm{ml}$ dung dịch chuẩn nội 3-pentanol và trộn. Bơm $2 \mu 1$ phần mẫu thử và các dung dịch chuẩn làm việc. Đo chiều cao pic của mỗi thành phần trong dung dịch chuẩn làm việc và tính tỷ lệ chiều cao pic của từng thành phần với dung dịch 
chuẩn nội. Tính tỷ lệ nồng độ của từng thành phần bằng cách chia khối lượng của chất chuẩn nội cho khối lượng của thành phần.

Dựng đồ thị của các tỷ lệ nồng độ trên trục hoành dựa theo các tỷ lệ chiều cao pic trên trục tung đối với mỗi loại alcohol bậc cao trong tất cả các chuẩn làm việc để thu được các đường chuẩn. Đối với etyl axetat, dựng chiều cao pic trực tiếp dựa theo nồng độ.

Tương tự, đo chiều cao pic của từng thành phần trên sắc đồ mẫu thử và tính tỷ lệ chiều cao pic. Đọc các tỷ lệ nồng độ của tất cả các loại alcohol, sử dụng đường chuẩn. Nhân tỷ lệ nồng độ của từng loại alcohol có trong phần mẫu thử với 40.76 để thu được số $\mathrm{g} / 100 \mathrm{ml}$. Cần phải dựng đường chuẩn mới khi sử dụng các thiết bị, các thông số hoặc các chất chuẩn mới.

Sử dụng máy sắc ký khí, được trang bị bộ detector ion hoá ngọn lửa, cột: glyxeron $2 \%$ và $1,2,6-$ hexanetriol $2 \%$. Ống nhồi dài $3 \mathrm{~m}$ và đường kính ngoài $3 \mathrm{~mm}$. Ổn định cột qua đêm trong lò ở $80^{\circ} \mathrm{C}$ với tốc độ dòng khí heli từ $10 \mathrm{ml} / \mathrm{min}$ đến $25 \mathrm{ml} / \mathrm{min}$ và detector ở cuối cột đã được tháo ra. Nhiệt độ cột là $80{ }^{\circ} \mathrm{C}$; nhiệt độ của bộ bơm mẫu là $100{ }^{\circ} \mathrm{C}$; Nhiệt độ detector là $125{ }^{\circ} \mathrm{C}$; Tốc độ dòng khí mang heli và hydro là $25 \mathrm{ml} / \mathrm{min}$, tốc độ không khí từ $250 \mathrm{ml} / \mathrm{min}$ đến $400 \mathrm{ml} / \mathrm{min}$.

\section{Phuoong pháp thủ kim loại nặng:}

Phương pháp xác định nguyên tố vết - Xác định chì, cadimi, crom, molypden bằng quang phổ hấp thụ nguyên tử bằng lò graphit (GFAAS) sau khi phân huỷ áp lực TCVN 7929: 2008 [17]

Vi sinh vật trong thực phẩm - Phương pháp định lượng Staphylococci có phản ứng dương tính với coagulase (Staphylococcus aureus và các loài khác) trên đĩa thạch - Phần 1: Kỹ thuật sử dụng môi trường thạch Baird-Parker TCVN 4830-1: 2005 [18]

Phuoong pháp phân tích và xủ lí số liệu: Giá trị trung bình cộng, tính phương sai và độ lệch chuẩn trên phần mềm Microsoft excel 2010

\section{Kết quả và thảo luận}

\section{Thành phần dịch quả sim}

Thành phần dịch quả của một giống sim mọc ở các vùng khác nhau, các mùa khác nhau và thời điểm thu hái khác nhau là khác nhau. Tuy nhiên sự sai khác đó là không nhiều và có thể chấp nhận được. Thành phần dịch quả sim dùng lên men rượu vang sim dùng trong các nghiên cứu này được ghi lại trong bảng 1 .

Bảng 1. Thành phần dịch quả sim thu hái tại xã Côn Lôn, huyện Na Hang, tỉnh Tuyên Quang tháng 8 năm 2019

\begin{tabular}{|c|l|c|}
\hline STT & Các chỉ tiêu hóa học & Kết quả \\
\hline 1 & Hàm lượng đường & $9.8 \pm 0.50 \mathrm{~g} / 1$ \\
\hline 2 & Hàm lượng acid tổng số & $0.9 \pm 0.20 \mathrm{~g} / 1$ \\
\hline 3 & Hàm lượng tanin & $1.4 \pm 0.01 \%$ \\
\hline 4 & Hàm lượng vitamin C & $0,9 \mathrm{mg} / 1$ \\
\hline
\end{tabular}

Thành phần hóa học trong dịch quả sim ở bảng 1 có hàm lượng đường cao $9.8 \mathrm{~g} / \mathrm{l}$, hàm lượng acid cao $0.9 \mathrm{~g} / \mathrm{l}$, rất thích hợp cho nấm men phát triển. Việc nghiên cứu sử dụng dịch quả sim làm nguyên liệu để sản xuất vang là hoàn toàn có cơ sở khoa học và phù hợp với điều kiện thực tế (nhiều loại quả có hàm lượng đường cao, giàu dinh dưỡng, vi lượng, tốt cho sức khỏe...) của Việt Nam [19], Thành phần của quả sim thu hái tại xã Côn Lôn, huyện $\mathrm{Na} \mathrm{Hang,} \mathrm{tỉnh}$ Tuyên Quang có hàm lượng đường cao và tanin hơn các công bố trong nước. Àm lượng acid tổng số và vitamin $\mathrm{C}$ thì tương đương.
Khảo sát và thử nghiệm sơ bộ ảnh hưởng của chất sát khuẩn trong lên men dịch quả sim, cho thấy hàm lượng $\mathrm{K}_{2} \mathrm{~S}_{2} \mathrm{O}_{5}$ từ $120-190 \mathrm{mg} / \mathrm{l}$ (tương ứng với hàm lượng $\mathrm{SO}_{2}$ là 70 - 110 p.p.m) đủ để ức chế hoạt động của nhiều loài vi khuẩn mà không ảnh hưởng đến sự sinh sản và phát triển của nhiều loại nấm men có trong môi trường, có thể tạo được nguồn giống nấm men để phân lập và tuyển chọn. $\mathrm{K}_{2} \mathrm{~S}_{2} \mathrm{O}_{5}$ với hàm lượng $156 \mathrm{mg} / \mathrm{l}$ (tương ứng với hàm lượng $\mathrm{SO}_{2}$ là 90 p.p.m) được bổ sung vào các môi trường để khử trùng. Dịch quả sim đạt yêu cầu là nguyên liệu chế biến thực phẩm [20] . Nước sử dụng trong lên men đạt tiêu 
chuẩn nước sạch sử dụng sản xuất thực phẩm. Lên men dịch quả sim bằng nấm men Saccharomyces cerevisiae S5 đã được nghiên cứu tuyển chọn, định danh, xác định độ an toàn theo quy trình sản xuất vang sim rừng $\mathrm{Na}$ Hang [1]. Sản phẩm rượu vang thu được được dùng làm đối tượng phân tích các chỉ tiêu lý hóa, vi sinh, cảm quan.

Thành phần hóa học của vang sim
Thành phần của vang khá phức tạp. Đến nay, trong hỗn hợp rượu vang có trên 300 thành phần các chất khác nhau đã được phát hiện. Thành phần chính của vang gồm có: nước, rượu etylic, ester, aldehyde, các acid amin, các vitamin, tro, acid tổng số, acid bay hơi, đường và các chất hoà tan khác. Trong giới hạn nghiên cứu, các thành phần hóa học chính trong vang sim rừng $\mathrm{Na}$ Hang được xác định và ghi lại trong bảng 2 .

Bảng 2. Các thành phần hóa học của vang sim

\begin{tabular}{|c|l|c|c|}
\hline STT & \multicolumn{1}{|c|}{ Tên chỉ tiêu } & Vang sim & $\begin{array}{c}\text { Mức giới hạn theo } \\
\text { quy định }\end{array}$ \\
\hline 1 & Hàm lượng ethanol (cồn) ở $20^{\circ} \mathrm{C}, \%$ thể tích, không nhỏ hơn & 12.5 & Không nhỏ hơn 8,5 \\
\hline 2 & Hàm lượng metanol, mg/l cồn $100^{\circ}$, không lớn hơn & 0 & 400 \\
\hline 3 & $\begin{array}{l}\text { Độ acid dễ bay hơi rượu vang đỏ có hàm lượng đường kính theo } \\
\text { tồng hàm lượng glucose và fructose nhỏ hơn } 5 \mathrm{~g} / 1\end{array}$ & 3.00 & 150 \\
\hline 4 & Hàm lượng rượu bậc cao mg/l & 328.32 & Tự công bố \\
\hline 5 & Hàm lượng ester $(\mathrm{mg} / \mathrm{l})$ & 281.92 & Tự công bố \\
\hline 6 & Hàm lượng aldehyde $(\mathrm{mg} / \mathrm{l})$ & 34.10 & Tự công bố \\
\hline
\end{tabular}

Thành phần hóa học của rượu vang sim được nêu ở bảng 2 bao gồm: hàm lượng ethanol, methanol, acid, ester, rượu bậc cao, aldehyde trong vang sim đều thấp hơn ngưỡng cho phép rất nhiều. Các chỉ tiêu được phép tự công bố có chỉ số phù hợp với vang tiêu chuẩn (QCVN 6-3:2010/BYT) [21]. Đặc biệt, không phát hiện metanol trong mẫu vang sim. Điều này có thể lý giải do trong dịch quả sim có rất ít pectin do đó lượng metanol sinh ra trong vang sim rất ít, dưới ngưỡng phát hiện. Trong khi đó, kết quả phân tích thành phần của hầu hết các loại vang đều có metanol, thành phần nguy hiểm gây hại cho người sử dụng, chỉ cần một lượng nhỏ có thể gây gây tổn thương võng mạc, tổn thương thần kinh thị giác, dẫn đến mù lòa, tổn thương não bộ, có thể dẫn đến tử vong. Hàm lượng methanol tối đa trong rượu không gây độc với người là $2 \% \mathrm{~V} / \mathrm{V}$ [22]. Các chỉ tiêu phân tích, cho phép kết luận: thành phần rượu vang sim rừng $\mathrm{Na}$ Hang đạt tiêu chuẩn vang Việt Nam.

\section{Thành phần kim loại nặng}

Thành phần kim loại nặng trong vang sim, được phân tích và ghi lại trong bảng 3 :

Bảng 3. Thành phần kim loại nặng trong rươu vang sim

\begin{tabular}{|c|l|c|c|}
\hline STT & \multicolumn{1}{|c|}{ Kim loại nặng } & Vang sim (mg/l) & $\begin{array}{c}\text { Mức giới hạn theo quy định } \\
(\mathbf{m g} / \mathbf{l})\end{array}$ \\
\hline 1 & Arsen (As) & $0.3 \pm 0.08$ & 1.0 \\
\hline 2 & Cadmi $(\mathrm{Cd})$ & $0.2 \pm 0.07$ & 2.0 \\
\hline 3 & Chì $(\mathrm{Pb})$ & $0.1 \pm 0.05$ & 0.5 \\
\hline 4 & Thuỷ ngân $(\mathrm{Hg})$ & $0.1 \pm 0.05$ & 1.0 \\
\hline 5 & Methyl thuỷ ngân $(\mathrm{MeHg})$ & $0.3 \pm 0.06$ & 2.0 \\
\hline
\end{tabular}

Các kêt quả phân tích ở bảng 3 về giới hạn tối đa hàm lượng kim loại nặng trong rượu vang sim đạt dưới ngương theo quy định hiện hành: Arsen $0.3 \pm 0.08$ $\mathrm{mg} / \mathrm{l}$, cadmi $0.2 \pm 0.07 \mathrm{mg} / \mathrm{l}$, chì $0.1 \pm 0.05 \mathrm{mg} / \mathrm{l}$, thủy ngân $0.1 \pm 0.05$, metyl thủy ngân $0.3 \pm 0.06 \mathrm{mg} / \mathrm{l}$ [4]. Các mức giới hạn này, không ảnh hưởng đến sức khỏe 
người tiêu dùng. Do đó, chúng ta hoàn toàn an tâm về thành hóa học của vang sim $\mathrm{Na}$ Hang.
Thành phần vi sinh vật trong vang sim được ghi lại trong bảng 4 .

\section{Thành phần vi sinh vật}

Bảng 4 . Các chỉ tiêu vi sinh của vang sim

\begin{tabular}{|c|c|c|c|}
\hline Tên chỉ tiêu & Vang sim & $\begin{array}{l}\text { Mức giới hạn theo } \\
\text { quy định }\end{array}$ & $\begin{array}{l}\text { Phân loại } \\
\text { chỉ tiêu } 1 \text { ) }\end{array}$ \\
\hline 1. Tổng số vi sinh vật hiếu khí, CFU/ml & $166 \pm 7$ & 1000 & A \\
\hline 2. E.coli, $\mathrm{CFU} / \mathrm{ml}$ & Không có & Không được có & A \\
\hline 3. Cl.perfringens, $\mathrm{CFU} / \mathrm{ml}$ & Không có & Không được có & A \\
\hline 4. Coliforms, $\mathrm{CFU} / \mathrm{ml}$ & Không có & Không được có & A \\
\hline 5. Strep.feacal, CFU/ml & Không có & Không được có & A \\
\hline $\begin{array}{l}\text { 6. Tổng số nấm men và nấm mốc, } \\
\text { CFU/ml sản phẩm }\end{array}$ & $4 \pm 0.2$ & 100 & A \\
\hline
\end{tabular}

Kết quả phân tích thành phần vi sinh vật trong vang sim bao gồm tổng vi sinh vật hiếu khí là $166 \pm 7$ $\mathrm{CFU} / \mathrm{ml}$, tổng số nấm men và nấm mốc $4 \pm 0.2$ $\mathrm{CFU} / \mathrm{ml}$, không phát hiện $\mathrm{E}$. coli, $\mathrm{Cl}$. perfringens, Strep. feacal trong vang sim. Khi phân tích độc tố vi nấm theo QCVN 8-1: 2011/BYT, Quy chuẩn kỹ thuật quốc gia đối với giới hạn ô nhiễm độc tố vi nấm trong thực phẩm, không phát hiện độc tố vi nấm ochratoxin A trong rượu vang sim. Các tiêu chí này phù hợp với tiêu chuẩn quy định về vi sinh cho đồ uống có cồn
QCVN 6-3: 2010/BYT [21]của Việt Nam. Hầu hết các công bố về rượu vang trên thị trường chỉ công bố một vài chỉ tiêu hóa học cơ bản. Các thành phần kim loại nặng, các chỉ tiêu vi sinh thường chỉ được cơ sở sản xuất ghi chép và theo dõi nội bộ, không công bố. Do đó, việc phân tích và so sánh các chỉ tiêu này ở rượu vang sim với các loại vang khác bị han chế. Công bố này cung cấp cái nhìn tổng thể cho người tiêu dùng về thành phần, chất lượng rượu vang sim rừng $\mathrm{Na} H a n g$.

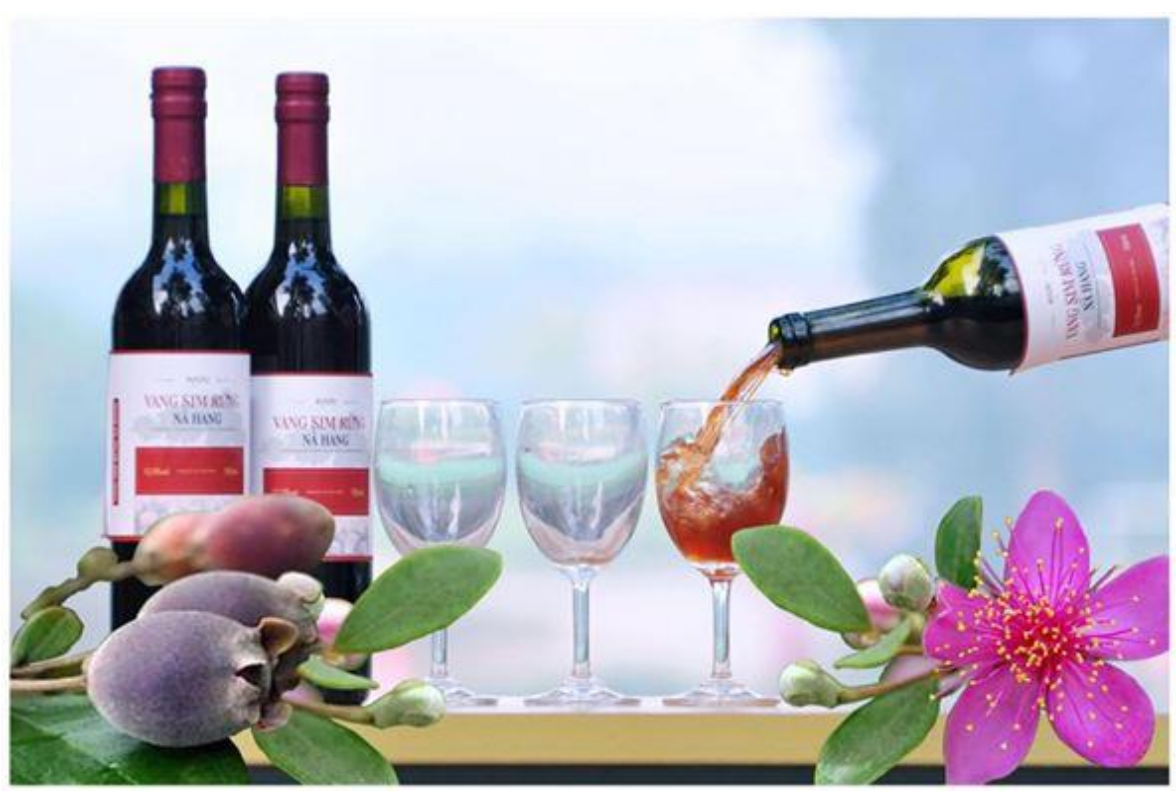

Hình 1. Vang sim thành phẩm chụp tại Truò̀ng Đại học Tân Trào, tỉnh Tuyên Quang tháng 10 năm 2019 


\section{KÊT LUậN:}

Bằng các phương pháp hiện đại, chính xác, có độ tin cậy cao, thành phần rượu vang sim rừng $\mathrm{Na} H a n g$, Tuyên Quang đã được xác định. Đây là công trình công bố đầu tiên về thành phần hóa học và vi sinh vật học của vang sim rừng $\mathrm{Na}$ Hang. Hầu hết các thành phần hóa học và vi sinh vật trong rượu vang sim này đều nhỏ hơn nhiều so với quy định của Việt Nam. Đặc biệt, trong thành phần của loại vang này, không có metanol, không có E. Coli, Ch. Perfringens, Coliforms, Stre. feacal, không có độc tố vi nấm ochratoxin $\mathrm{A}$. Thành phần hóa học khác của rượu vang sim gồm ethanol $12.5 \mathrm{~g} / \mathrm{l}$, acid bay hơi $3 \mathrm{mg} / \mathrm{l}$, hàm lượng rượu bậc cao $328.32 \mathrm{mg} / \mathrm{l}$, hàm lượng ester 281.92 $\mathrm{mg} / \mathrm{l}$, hàm lượng aldehyde $34.1 \mathrm{mg} / \mathrm{l}$, arsen $0.3 \pm 0.08$ $\mathrm{mg} / \mathrm{l}$, cadmi $0.2 \pm 0.07 \mathrm{mg} / \mathrm{l}$, chì $0.1 \pm 0.05 \mathrm{mg} / \mathrm{l}$, thủy ngân $0.1 \pm 0.05$, metyl thủy ngân $0.3 \pm 0.06 \mathrm{mg} / \mathrm{l}$. Chỉ tiêu vi sinh vật của rượu vang sim gồm: vi sinh vật hiếu khí là $166 \pm 7 \mathrm{CFU} / \mathrm{ml}$, tổng số nấm men và nấm mốc 4 $\pm 0,2 \mathrm{CFU} / \mathrm{ml}$. Rượu vang sim có cảm quan tốt. Các chỉ tiêu này là cơ sở khoa học để thiết lập thành bộ tiêu chí công bố chất lượng rượu vang sim rừng $\mathrm{Na} \mathrm{Hang}$, đưa ra thị trường sản phẩm có chất lượng đặc trưng cho quê hương $\mathrm{Na} \mathrm{Hang}$, đưa cây sim từ cây hoang dại thành cây có giá trị kinh tế cho bà con địa phương.

\section{TÀI LIỆ THAM KHẢO}

1. Hoang Thi Le Thuong. Research on selection of yeast strains for wine production from Sim fruit (Rhodomyrtus tomentosa) in Con Lon commune, $\mathrm{Na}$ Hang district. Final report of the project grassroots level 2019, p.2

2. Bird D., Understanding wine technology: the science of wine explained. Board and Bench Publishing, 2011, p.28.

3. Legras J.L, et al., Bread, beer and wine: Saccharomyces cerevisiae diversity reflects human history, Molecular ecology 16(10) 2007 p. 2091.

4. Vietnam Alcohol and Beverage Association. Conference: Vietnam Alcohol and Beverage Association, Vietnam wine market: There is still great potential, 2014.

5. $\mathrm{Vu}$ Cong Hau.Technological process of producing fruit wine in the family: oranges; grapefruit; toad (Yunnan crocodile); wild strawberry; mulberry; pineapple; dig; Passionflower; mangosteen; plum; dream; grapes; mango; apple; fabric. Final report of the state-level project, 2017, p.14.
6. Dang Hong Anh, Nguyen Thi Hoai Tram, Le Thanh Mai. Selection of yeast strains for wine fermentation in Vietnam. Scientific conference. Hanoi, 2006 p.6.

7. Boulton, R.B., et al., Principles and practices of winemaking. Springer Science \& Business Media 6(3) 1999 p.251.

8. Jin, G.m., C.p. Lin, and R. Zhong, Research on the stability of the flavonoid glycosides during the fermentation process of the rhodomyrtus tomemtosa wine [J]. Food Science and Technology, 2006, p5.

9. Fenglin, H. and Z.S.L. Ruili, Preparation of wine from the Berries of Downy Rosemyrtle. Economic Forest Reseaches, 1997, p2.

10. Nguyen Van Binh. Report on acceptance of the grassroots-level project: Research on wine production (Rhodomyrtus tomentosa) .University of Agriculture and Forestry, Thai Nguyen, 2012.

11. National standards, Determination of tannin according to Vietnam Standard - Tanin 2020, Hanoi.

12. National standard 11672: 2016 - Determination of vitamin C (reduced ascorbic acid) - Titration method, 2016.

13. National standards, Determination of total acid according to TCVN 8012: 2009, 2016.]

14. National standards, Distilled alcohol Determination of alcohol concentration, Hanoi, 2009.]

15. National standard, Distilled alcohol: Determination of total aldehydes, Hanoi, 2009.

16. National standard TCVN 8011: 2009 on Distilled wine - Method of determination of high alcohol content and ethyl acetate by gas chromatography, Hanoi, 2016.

17. National standard TCVN 7929: 2008 (EN 14083: 2003) about Food - Determination of trace elements - Determination of lead, cadmium, chromium, molybdenum by atomic absorption spectrometer using graphite furnace (GFAAS) after pressure decomposition, Hanoi, 2017

18. Vietnamese standard, Microorganisms in food and animal feeds - Enumeration method Staphylococci positively reacts with coagulase on agar plates - Part 1: Technique using Baird - parker agar environment, Hanoi, 2005. 
19. Ngo Minh Thuy. Stabilizing and enhancing the quality of sim wine by chemical and biological methods. Journal of Science, Can Tho University, 2010: p.165.

20. Foodstuffs Commission Regulation (EC) No 1881/2006 of 19 December 2006 setting maximum levels for certain contaminants in foodstuffs.
21. Ministry of Health, National technical regulations for alcoholic beverages QCVN 6-3: 2010 / BYT, 2010.

22. Paine, A.J. and A.D. Dayan, Defining a tolerable concentration of methanol in alcoholic drinks. Human \& Experimental Toxicology, 20(11)

\section{Study on the chemical composition and microbiology of sim wine collected in Con Lon commune, Na Hang district, Tuyen Quang province}

Hoang Thi Le Thuong

\begin{tabular}{l}
\hline Article info \\
\hline Recieved: \\
$7 / 6 / 2020$ \\
Accepted: \\
12/8/2020
\end{tabular}

Keywords: Rhodomyrtus tomentosa, Saccharomyces cerevisiae, rươu vang.

\begin{abstract}
Wine is alcoholic beverage that is fermented directly from the juice without undergoing distillation. Rhodomyrtus tomentosa ( $R$. tomentosa) wild Sim wine of $\mathrm{Na}$ Hang is produced from Sim fruit juice ( $R$. tomentosa) using the yeast strain Saccharomyces cerevisiae S5 which has been selected and identified according to the process of producing wild tomentosa wine of $\mathrm{Na}$ Hang. With the desire to develop a set of quality declaration criteria for $R$. tomentosa wine, the physicochemical composition and microorganisms of $R$. tomentosa, wine is determined by modern analytical methods in accordance with regulations. The resulting $R$. tomentosa wine has physical and chemical criteria (ethanol $12.5 \mathrm{~g} / \mathrm{l}$, volatile acid $3.00 \mathrm{mg} / \mathrm{l}$, high alcohol content $328.32 \mathrm{mg} / \mathrm{l}$, ester content 281.92 $\mathrm{mg} / \mathrm{l}$, content of aldehydes $34.1 \mathrm{mg} / \mathrm{l}$, no methanol), microorganisms (aerobic microorganisms is $166 \pm 7 \mathrm{CFU} / \mathrm{ml}$, total yeast and molds $4 \pm 0.2 \mathrm{CFU} / \mathrm{ml}$, not found E. coli, Cl. perfringens, Strep. feacal) and good sensory value. The composition of Na Hang $R$. tomentosa wine meets the Vietnamese wine standard.
\end{abstract}

